\title{
Indirect costs associated with surgery for low back pain-a secondary analysis of clinical trial data.
}

\author{
Reginald Fayssoux \\ Drexel University, College of Medicine \\ Neil I Goldfarb \\ Jefferson School of Population Health, Thomas Jefferson University \\ Alexander R Vaccaro \\ Departments of Orthopaedic and Neurological Surgery, Thomas Jefferson University Hospital \\ James Harrop \\ Departments of Orthopaedic and Neurological Surgery, Thomas Jefferson University Hospital
}

Follow this and additional works at: https://jdc.jefferson.edu/healthpolicyfaculty

Part of the Health Services Research Commons
Let us know how access to this document benefits you

\section{Recommended Citation}

Fayssoux, Reginald; Goldfarb, Neil I; Vaccaro, Alexander R; and Harrop, James, "Indirect costs associated with surgery for low back pain-a secondary analysis of clinical trial data." (2010). College of Population Health Faculty Papers. Paper 58.

https://jdc.jefferson.edu/healthpolicyfaculty/58

This Article is brought to you for free and open access by the Jefferson Digital Commons. The Jefferson Digital Commons is a service of Thomas Jefferson University's Center for Teaching and Learning (CTL). The Commons is a showcase for Jefferson books and journals, peer-reviewed scholarly publications, unique historical collections from the University archives, and teaching tools. The Jefferson Digital Commons allows researchers and interested readers anywhere in the world to learn about and keep up to date with Jefferson scholarship. This article has been accepted for inclusion in College of Population Health Faculty Papers by an authorized administrator of the Jefferson Digital Commons. For more information, please contact: JeffersonDigitalCommons@jefferson.edu. 


\title{
Indirect Costs Associated with Surgery for Low Back Pain-A Secondary Analysis of Clinical Trial Data
}

\author{
Reginald Fayssoux, M.D., ${ }^{1}$ Neil I. Goldfarb, ${ }^{2}$ Alexander R. Vaccaro, M.D., ${ }^{3}$ and James Harrop, M.D. ${ }^{3}$
}

\begin{abstract}
This study examines the indirect costs associated with surgery for axial low back pain using data obtained from a prospective multicenter clinical trial that compared Charité artificial disc replacement with anterior lumbar interbody fusion using iliac crest bone graft. While $75 \%$ of study subjects reported full- or part-time employment prior to surgery, this percentage dropped to $45 \%$ at 6 weeks postoperatively. Return to preoperative employment levels occurred at approximately 6 months postoperatively. Two years after surgery, employment levels were $16 \%$ higher than preoperative levels. Lost productivity related to absenteeism resulted in lost wages averaging \$2884 per patient during the first postoperative year. Although short-term indirect costs of surgery are substantial from a societal perspective, the higher employment rate at 2 years suggests a long-term economic benefit. The findings demonstrate the significant, though not surprising, impact of spinal disability on productivity, and the importance of including measurement of lost productivity and return to work in the economic evaluation of related interventions. (Population Health Management 2010;13:9-13)
\end{abstract}

\section{Introduction}

$\mathbf{T}$ HERE IS SPARSE LITERATURE REGARDING PATIENTS' ABILITY to return to work following spinal surgery for axial low back pain (LBP). Specifically, the time frame for return to work, as well as factors associated with preoperative and postoperative employment, are unknown. The indirect costs associated with the postoperative recovery period for these interventions also have not been determined. With health care costs continuing to rise, economic considerations such as these are becoming increasingly important in decisions regarding treatment alternatives and the allocation of health care resources, ${ }^{1}$ especially in the care of the patient with back pain.

The societal costs of back pain are dramatic. It has become the second most common reason for a visit to a primary care provider. Back pain is widely prevalent and afflicts $80 \%$ of the population 60 years of age and older. The percentage of patients with acute LBP who ultimately progress to chronic LBP has been estimated to be anywhere from $2 \%$ to $34 \%{ }^{2}$ A small subset of these patient may benefit from operative intervention for back pain. In the workforce, lumbar back pain remains one of the greatest contributors to health-related loss of productivity. Previous estimates of health care expendi- tures for LBP in the United States have been conservatively

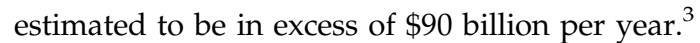

Chronic LBP, defined as longer than 3 months of symptoms, is generally regarded as having a poorer prognosis than acute back pain. ${ }^{4}$ The sum of the literature suggests that surgery for axial lumbar back pain can have successful outcomes for carefully selected patients. A variety of procedures aimed at alleviating chronic LBP without radiculopathy have been utilized. In the setting of single-level degenerative disc disease, the most common surgical treatment is fusion of the involved spinal segments, though results are inconsistent. ${ }^{5}$ Due to technological advancements, a recent alternative is total disc replacement surgery, though long-term data regarding efficacy are limited. ${ }^{6}$ Unfortunately, these recent advancements in spine surgery have seen the introduction of newer, more costly implants and procedures. The soaring costs of spinal implants and biologic adjuncts to fusion have resulted in increased scrutiny of the clinical and economic impact of these interventions.

Costs related to an operative intervention can be divided into direct costs (ie, costs associated with direct medical treatment including surgery and postoperative monitoring) and indirect costs (ie, costs associated with lost productivity due to illness). Direct costs typically are viewed from either a

\footnotetext{
${ }^{1}$ Department of Orthopaedic Surgery, Drexel University College of Medicine, Philadelphia, Pennsylvania.

${ }^{2}$ Jefferson School of Population Health, Philadelphia, Pennsylvania.

${ }^{3}$ Departments of Orthopaedic and Neurological Surgery, Thomas Jefferson University Hospital, Philadelphia, Pennsylvania.
} 
provider (hospital and/or physician) or payer (insurer) perspective. From the provider perspective, direct costs include costs related to the hospitalization including facility costs, therapy costs, costs of diagnostic testing, and medical device costs. Additional direct medical costs from the provider perspective include the cost of the surgeon's time. From the payer perspective, direct costs include facility and physician costs related to the hospitalization as well as costs related to follow-up care and the management of postoperative complications.

In contrast, indirect costs are more difficult to determine and relate to lost workforce productivity resulting from absence at work (absenteeism) or decreased productivity at work (presenteeism). Numerous studies have cited multiple factors associated with return to work following an episode of LBP that was treated nonoperatively. ${ }^{7-9}$ To our knowledge, the time frame for return to work and factors associated with preoperative and postoperative employment status following surgery for LBP have not been previously described, nor has an estimate of the indirect costs related to these procedures been previously published.

Recently, clinical trial data have become available from a prospective multicenter study that compared the safety and effectiveness of the Charité artificial lumbar disc to anterior lumbar interbody fusion (ALIF) using threaded cages with iliac crest bone graft (ICBG) for the treatment of single-level degenerative disc disease at L4-L5 or L5-S1. Guyer and colleagues ${ }^{10}$ analyzed this data comparing the direct costs of the 2 procedures used in the clinical trial from both hospital and payer perspectives. They found the overall economic effect of 1-level total disc replacement on hospitals and payers to be roughly equivalent to 1-level fusion.

From the provider/hospital perspective, the cost of operative intervention was $\$ 16,600$ for the Charité artificial disc and $\$ 18,600$ for ALIF with ICBG. From a payer perspective, direct costs were examined from 2 different points of view, a Diagnosis Related Group (DRG) payment arm and a per diem payment arm. The hospital costs from a DRG payment arm perspective were $\$ 17,600$ for the Charité artificial disc and $\$ 33,000$ for ALIF with ICBG. Costs from a per diem payment arm perspective were $\$ 24,900$ for the Charite artificial disc and $\$ 23,800$ for ALIF with ICBG, though for consistency these figures were based on $100 \%$ reimbursement of spinal implant costs across all comparators in the study. Regardless, the direct costs related to operative treatment of single-level degenerative disc disease are significant.

In an effort to add to this discussion regarding the economics of operative intervention for LBP, we analyzed the clinical trial data comparing the Charité artificial disc and ALIF with ICBG procedures to estimate the time frame for and factors associated with return to work and to estimate the indirect costs of surgery for LBP due to absenteeism.

\section{Methods}

We prospectively reviewed the clinical data from a noninferiority trial of 304 patients randomized in a 2:1 ratio to receive either the Charite artificial disc replacement (205 patients) or ALIF with ICBG (99 patients). Inclusion and exclusion criteria for this study were strict in an effort to include only those patients with back pain, leg pain, or both (but without radiculopathy) secondary to single-level de- generative disc disease at L4-L5 or L5-S1, while minimizing potentially confounding variables. ${ }^{11}$ These criteria have been published previously.

Data included results of the Visual Analog Scale (VAS) for pain, the Oswestry Disability Index (ODI), and the Short Form (SF)-36 health survey recorded preoperatively, postoperatively, at 6 weeks, and at 3, 6, 12, and 24 months after surgery. The employment status of enrolled subjects was categorized at these same time intervals as: full time, part time, long-term disability leave, short-term disability leave, unemployed, retired, and other (none of the above).

In order to better understand patient characteristics predicting return to work, a logistic regression model was constructed. Several variables were screened for inclusion in the model including sex, age, body mass index (BMI), treatment received, baseline employment, normal activity level, pain medication use, baseline and 24-month postoperative ODI score, baseline and 24-month postoperative VAS score, and baseline and 24-month postoperative SF-36 score. The variables were pared down using hierarchical elimination. The final model included sex, age, treatment, baseline employment, and 24-month postoperative ODI and SF-36 Physical and Mental Health Composite scores. The adequacy of this model was verified using the Hosmer Lemeshow goodness-of-fit test.

Indirect costs related to absenteeism were estimated by determining the level of productivity at each follow-up. In order to better understand the economic impact of these changes in productivity, the estimated earnings for patients who underwent each procedure were calculated at each follow-up. The average weekly salary for both treatment groups was calculated using age-adjusted weekly salaries based on national averages from the US Bureau of Labor Statistics. These salaries were prorated for those who worked part time. The average weekly salary was then calculated overall and for both treatment groups at each follow-up. Indirect costs related to absenteeism were estimated as the wages lost as a result of absence from work.

Aggregate data was provided by Depuy Spine (DePuy Spine, Inc., Raynham, MA). Institutional Review Board approval was received for this study. Data were analyzed using Microsoft Excel 2002 (Microsoft Corporation, Redmond, WA) and SPSS v16.0 statistical software package (SPSS Inc., Chicago, IL).

\section{Results}

Patient demographics for the study population are presented in Table 1 . The average age of enrolled subjects was 39.6 years. The majority were white $(>85 \%)$, and most subjects were physically active $(>85 \%)$. There were some minor differences between groups with fusion patients having a slightly higher degree of obesity, slightly more female subjects, and slightly more minority patients. The overall mean preoperative ODI, VAS, and SF-36 scores were equivalent between groups (Table 2) and reflected significant disability.

We determined the number of subjects who worked full or part time prior to surgery as a percentage of the entire study population and also as a percentage of the study population on payroll (ie, currently working or receiving employer paid short-term and long-term disability). The percentage of the entire study population who worked full or part time prior 
Table 1. Patient Demographics

\begin{tabular}{|c|c|c|c|c|c|}
\hline Category & Characteristic & Charité & $\%$ & ALIF with ICBG & $\%$ \\
\hline Total & & 205 & $100.0 \%$ & 99 & $100.0 \%$ \\
\hline Age, categorical & $\begin{array}{l}18-24 \\
25-44 \\
45-64 \\
65+\end{array}$ & $\begin{array}{r}7 \\
142 \\
56 \\
0\end{array}$ & $\begin{array}{r}3.4 \% \\
69.3 \% \\
27.3 \% \\
0.0 \%\end{array}$ & $\begin{array}{r}1 \\
68 \\
30 \\
0\end{array}$ & $\begin{array}{r}1.0 \% \\
68.7 \% \\
30.3 \% \\
0.0 \%\end{array}$ \\
\hline Age, mean and SD & & $39.6(8.16)$ & & $39.6(9.07)$ & \\
\hline 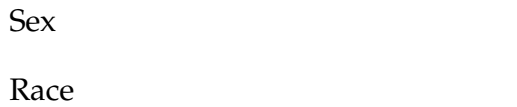 & $\begin{array}{l}\text { male } \\
\text { female } \\
\text { white }\end{array}$ & $\begin{array}{r}113 \\
92 \\
188\end{array}$ & $\begin{array}{l}55.1 \% \\
44.9 \% \\
91.7 \%\end{array}$ & $\begin{array}{l}44 \\
55 \\
87\end{array}$ & $\begin{array}{l}44.4 \% \\
55.6 \% \\
87.9 \%\end{array}$ \\
\hline & $\begin{array}{l}\text { black } \\
\text { Asian } \\
\text { Hispanic } \\
\text { other }\end{array}$ & $\begin{array}{l}8 \\
0 \\
0 \\
9\end{array}$ & $\begin{array}{l}3.9 \% \\
0.0 \% \\
0.0 \% \\
4.4 \%\end{array}$ & $\begin{array}{l}5 \\
0 \\
0 \\
7\end{array}$ & $\begin{array}{l}5.1 \% \\
0.0 \% \\
0.0 \% \\
7.1 \%\end{array}$ \\
\hline Body mass index & $\begin{array}{l}<18.5 \\
18.6-24 \\
25-29 \\
>30\end{array}$ & $\begin{array}{r}4 \\
83 \\
83 \\
35\end{array}$ & $\begin{array}{r}2.0 \% \\
40.5 \% \\
40.5 \% \\
17.1 \%\end{array}$ & $\begin{array}{r}1 \\
33 \\
37 \\
28\end{array}$ & $\begin{array}{r}1.0 \% \\
33.3 \% \\
37.4 \% \\
28.3 \%\end{array}$ \\
\hline Concomitant diseases & $\begin{array}{l}\text { Anemia } \\
\text { Angina } \\
\text { Asthma } \\
\text { Cancer } \\
\text { COPD } \\
\text { Hepatitis } \\
\text { Hypertension } \\
\text { Liver disease } \\
\text { Osteoarthritis } \\
\text { Others } \\
\text { Peptic ulcer } \\
\text { Seizures } \\
\text { Type I diabetes } \\
\text { Type II diabetes } \\
\text { Urinary tract infection }\end{array}$ & $\begin{array}{r}7 \\
2 \\
16 \\
2 \\
2 \\
6 \\
16 \\
0 \\
11 \\
93 \\
7 \\
2 \\
1 \\
5 \\
5\end{array}$ & $\begin{array}{r}3.4 \% \\
1.0 \% \\
7.8 \% \\
1.0 \% \\
1.0 \% \\
2.9 \% \\
7.8 \% \\
0.0 \% \\
5.4 \% \\
45.4 \% \\
3.4 \% \\
1.0 \% \\
0.5 \% \\
2.4 \% \\
2.4 \%\end{array}$ & $\begin{array}{r}5 \\
1 \\
9 \\
3 \\
1 \\
6 \\
14 \\
2 \\
3 \\
41 \\
3 \\
2 \\
1 \\
2 \\
0\end{array}$ & $\begin{array}{r}5.1 \% \\
1.0 \% \\
9.1 \% \\
3.0 \% \\
1.0 \% \\
6.1 \% \\
14.1 \% \\
2.0 \% \\
3.0 \% \\
41.4 \% \\
3.0 \% \\
2.0 \% \\
1.0 \% \\
2.0 \% \\
0.0 \%\end{array}$ \\
\hline Normal activity level prior to injury & $\begin{array}{l}\text { Active } \\
\text { Moderate } \\
\text { Light } \\
\text { Minimal }\end{array}$ & $\begin{array}{r}188 \\
15 \\
1 \\
1\end{array}$ & $\begin{array}{r}91.7 \% \\
7.3 \% \\
0.5 \% \\
0.5 \%\end{array}$ & $\begin{array}{r}86 \\
11 \\
2 \\
0\end{array}$ & $\begin{array}{r}86.9 \% \\
11.1 \% \\
2.0 \% \\
0.0 \%\end{array}$ \\
\hline
\end{tabular}

ALIF, anterior lumbar interbody fusion; COPD, chronic obstructive pulmonary disease; ICBG, iliac crest bone graft.

to surgery averaged 55\% overall (53\% for the Charité group and $57 \%$ for the fusion group). The percentage of subjects on payroll averaged $75 \%$ ( $75 \%$ for the Charité group and $77 \%$ for the fusion group).

Table 2. Overall Mean Preoperative Oswestry Disabiliy Index, Visual Analog Scale, AND SHORT FORM-36 SCORES

\begin{tabular}{lcc}
\hline & Charité & Fusion \\
\hline $\begin{array}{l}\text { Oswestry Disability } \\
\quad \text { Index (0 to 100\%) }\end{array}$ & 50.6 & 52.1 \\
$\begin{array}{l}\text { Visual Analog } \\
\quad \text { Scale (0 to 100) }\end{array}$ & 72.0 & 71.8 \\
$\begin{array}{l}\text { Short Form-36 Physical } \\
\quad \text { Component Summary (0 to 100) }\end{array}$ & 30.9 & 31.4 \\
$\begin{array}{l}\text { Short Form-36 Mental } \\
\quad \text { Component Summary (0 to 100) }\end{array}$ & 42.6 & 39.1 \\
\hline
\end{tabular}

As would be expected, immediately after surgery there was a substantial decrease in the number of subjects who worked full or part time. However, at 6 weeks postoperatively, the percentage of the entire study population who were working full or part time averaged $24 \%$ overall $(26 \%$ for the Charite group and $24 \%$ for the fusion group). The percentage of subjects on payroll who were working full or part time averaged $40 \%$ (41\% for the Charite group and $37 \%$ for the fusion group). There was a gradual increase over the 2year follow-up period (Fig. 1). Stratification to include only those subjects on payroll prior to surgery showed the Charité group tended to have a slightly higher percentage working at each follow-up. Using a linear regression model, return to baseline preoperative employment levels occurred approximately 6 months postoperatively for the entire study population and for workers on payroll in both groups. At 24 months, the percentage of the entire study population who were employed full or part time had increased $16 \%$ (ie, from $54.3 \%$ to $63.2 \%$ ) when compared to the baseline preoperative 


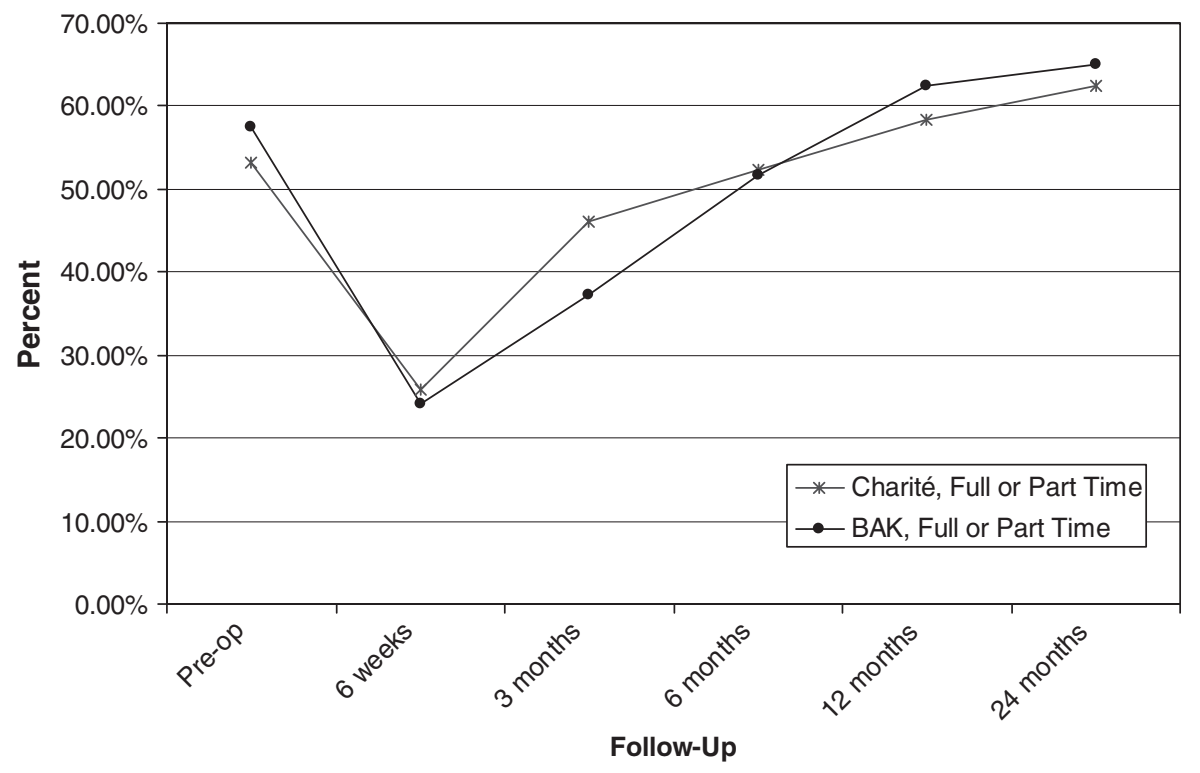

FIG. 1. Percentage of patients working during each follow-up period.

employment rate. Likewise, at 24 months, the percentage of subjects on payroll who were employed full or part time had increased $3 \%$ (ie, from $72.4 \%$ to $74.8 \%$ ) when compared to the baseline preoperative employment rate.

Logistic regression analysis showed, not surprisingly, that being employed at baseline was a strong predictor of return to work; however, other baseline characteristics such as BMI, pain medication use, or function as measured by ODI or SF36 were not significant independent predictors. Recovery at 24 months, as measured by ODI and SF-36 Mental Component Summary (MCS) score, also was shown to be closely associated with return to work (Table 3).

In order to better understand the economic impact of the changes in productivity, the estimated earnings for patients who underwent each procedure were calculated at each follow-up using US Bureau of Labor Statistics data (Fig. 1). The average weekly salary for full-time workers was estimated to be $\$ 728$ overall, $\$ 725$ for the Charité group, and $\$ 735$ for the fusion group. In general, weekly salaries were greater in the Charité group than the fusion group at each

Table 3. Logistic Regression Results for Prediction OF RETURN TO WORK

\begin{tabular}{lccc}
\hline Parameter & Estimate & $\begin{array}{c}\text { Standard } \\
\text { error }\end{array}$ & P-Value \\
\hline Intercept & 1.0459 & 1.3467 & 0.4374 \\
Gender & -0.199 & 0.1808 & 0.2712 \\
Age & -0.018 & 0.0204 & 0.3779 \\
Treatment & 0.2801 & 0.2004 & 0.1622 \\
Baseline employment & 1.0615 & 0.1845 & $<.0001$ \\
24-month ODI & -0.0449 & 0.0105 & $<.0001$ \\
24-month mental component & 0.035 & 0.0174 & 0.0448 \\
$\quad$ & & & \\
\hline
\end{tabular}

ODI, Oswestry Disability Index. follow-up, despite the lower estimated earning potential in the Charité group. Lost productivity related to absenteeism for this study population resulted in costs to society averaging \$2884 per patient in the first year following surgery.

\section{Discussion}

We analyzed prospectively collected data from a multicenter trial that compared Charité with fusion in order to establish the time frame for return to work and factors associated with preoperative and postoperative employment status, and to estimate the indirect costs of surgery for LBP related to absenteeism. We found only $75 \%$ of subjects on payroll (ie, currently working or receiving employer paid short- or long-term disability) were working full or part time prior to surgery. A significant drop occurred in the percentage of patients reporting full- or part-time employment 6 weeks after surgery, with a gradual increase over the following 2 years. Return to preoperative productivity levels occurred between 6 and 12 months postoperatively. Two years postoperatively the employment status had increased approximately $16 \%$. Given the delay in return to productivity related to absenteeism, the short-term indirect costs from a societal perspective are substantial; however, the higher employment status at 2 years suggests a long-term benefit. Further research in this regard is needed.

The low preoperative employment rate of patients is not surprising given that nearly $80 \%$ of patients had preoperative ODIs of $40 \%$ or greater, values associated with severe disability. The delay in return to preoperative productivity levels likely resulted from the postoperative rehabilitation associated with anterior lumbar spine surgery. The relatively lower success rate of operative treatment of isolated axial back pain certainly played a role as well. This delay in productivity resulted in significant costs in the short term. 
Logistic regression analysis showed that, of the limited number of candidate predictive variables that were available for this analysis, few were predictive of return to work. Baseline employment status, improvement in functional status as measured by the ODI, and improvement in MCS on the SF-36 were associated with return to work. While this finding is largely intuitive, it does suggest that postsurgical interventions, such as physical and occupational therapy, may hasten return to work, although clearly this conclusion is speculative.

The indirect costs related to absenteeism of surgery for LBP in this study population were $\$ 2,884$ per patient during the first postoperative year. The majority of these indirect costs were related to absenteeism in the first several postoperative months as employment rates reached baseline at approximately 6 months postoperatively. Currently, data regarding indirect costs of spinal surgery are lacking. As economic considerations become an increasingly important issue, cost effectiveness evaluations will find increasing importance in the surgical literature of the spine. This article adds to the literature a rough measure of the indirect costs associated with spine surgery for LBP.

This article has several limitations. The full analysis of indirect costs requires consideration of costs related to presenteeism. Unfortunately, there were no data to allow for this determination. Additionally, the criteria for inclusion into the clinical trial were fairly strict in an effort to include only subjects with single-level degenerative disc disease without radiculopathy, while limiting confounding factors. These strict criteria may have resulted in an overestimation of indirect costs because subjects in this clinical trial had relatively severe disease. Finally, because actual salary data were not collected in the clinical trial, the estimation of average weekly salaries was based on age-adjusted data from the US Bureau of Labor Statistics. Therefore, the information on lost productivity costs presented here is a crude estimate; however, the findings do demonstrate the importance of including productivity measures in cost-effectiveness evaluations of LBP interventions.

In conclusion, a significant drop in employment follows surgery for axial LBP with either procedure; this may persist for close to 1 year postoperatively. By 2 years post surgery, employment rates increased to levels that exceeded those prior to surgery. Return to work after surgery may be predicted by preoperative employment status and ODI and SF-36 MCS outcomes at 24-months follow-up. The indirect costs related to absenteeism as a result of surgery for LBP are substantial, averaging just over $\$ 2800$ per patient during the first postoperative year with the majority of the loss incurred in the first several months following surgery. These findings demonstrate the significant, though not surprising, impact of spinal disability on productivity, and the importance of including the measurement of lost productivity and return to work in the effectiveness and costeffectiveness evaluation of operative (and nonoperative) interventions.

\section{Disclosure Statement}

Dr. Fayssoux and Mr. Goldfarb disclose no conflicts of interest. Dr Vaccaro is a consultant with DePuy Spine and has received royalties in the past from the Charite device. Dr Harrop is a consultant with DePuy. Support for this research was provided through a grant from Depuy Spine.

\section{References}

1. Bozic KJ, Rosenberg AG, Huckman RS, Herndon JH. Economic evaluation in orthopaedics. J Bone Joint Surg Am 2003;85-A:129-142.

2. Steenstra IA, Verbeek JH, Heymans MW, Bongers PM. Prognostic factors for duration of sick leave in patients sick listed with acute low back pain: A systematic review of the literature. Occup Environ Med 2005;62:851-860.

3. Luo X, Pietrobon R, Sun SX, Liu GG, Hey L. Estimates and patterns of direct health care expenditures among individuals with back pain in the United States. Spine 2004;29:79-86.

4. Deyo RA, Weinstein JN. Low back pain. N Engl J Med 2001;344:363-370.

5. Turner JA, Ersek M, Herron L, Deyo R. Surgery for lumbar spinal stenosis. Attempted meta-analysis of the literature. Spine 1992;17:1-8.

6. Madigan L, Vaccaro AR, Spector LR, Milam RA. Management of symptomatic lumbar degenerative disk disease. J Am Academy Orthop Surg 2009;17:102-111.

7. Du Bois M, Szpalski M, Donceel P. Patients at risk for long-term sick leave because of low back pain. Spine J 2009;9:350-359.

8. Alexopoulos EC, Konstantinou EC, Bakoyannis G, Tanagra D, Burdorf A. Risk factors for sickness absence due to low back pain and prognostic factors for return to work in a cohort of shipyard workers. Eur Spine J 2008;17:11851192.

9. Heymans MW, Anema JR, van Buuren S, Knol DL, van Mechelen W, de Vet HC. Return to work in a cohort of low back pain patients: Development and validation of a clinical prediction rule. J Occup Rehabil 2009;19:155-165.

10. Guyer RD, Tromanhauser SG, Regan JJ. An economic model of one-level lumbar arthroplasty versus fusion. Spine J 2007;7:558-562.

11. Blumenthal S, McAfee PC, Guyer RD, et al. A prospective, randomized, multicenter Food and Drug Administration investigational device exemptions study of lumbar total disc replacement with the CHARITÉ artificial disc versus lumbar fusion: Part I: Evaluation of clinical outcomes. Spine 2005;30:1565-1575.
Address correspondence to: Neil I. Goldfarb Associate Dean for Research Jefferson School of Population Health 1015 Walnut Street, Suite 115 Philadelphia, PA 19107

E-mail: neil.goldfarb@jefferson.edu 

This article has been cited by:

1. Matthew F. Gornet, J. Kenneth Burkus, Randall F. Dryer, John H. Peloza. 2011. Lumbar Disc Arthroplasty with MAVERICK ${ }^{\mathrm{TM}}$ Disc Versus Stand-Alone Interbody Fusion. Spine 1. [CrossRef] 